\title{
Superhard, conductive coatings for atomic force microscopy cantilevers
}

\author{
C. Ronning, a) O. Wondratschek, M. Büttner, and H. Hofsäss \\ II. Physikalisches Institut, Universität Göttingen, Bunsenstr. 7-9, D-37073 Göttingen, Germany \\ J. Zimmermann, P. Leiderer, and J. Boneberg \\ Fachbereich Physik, Universität Konstanz, Postfach M676, D-78457 Konstanz, Germany
}

(Received 1 May 2001; accepted for publication 21 August 2001)

\begin{abstract}
Boron carbide thin films were grown by mass selected ion beam deposition using low energy ${ }^{11} \mathrm{~B}^{+}$ and ${ }^{12} \mathrm{C}^{+}$ions at room temperature. The amorphous films exhibit any desired stoichiometry controlled by the ion charge ratio $\mathrm{B}^{+} / \mathrm{C}^{+}$. Films with a stoichiometry of $\mathrm{B}_{4} \mathrm{C}$ showed the optimal combination of a high mechanical strength and a low electrical resistivity for the coating of atomic force microscopy (AFM) silicon cantilevers. The properties of such AFM tips were evaluated and simultaneous topography and Kelvin mode AFM measurements with high lateral resolution were performed on the systems (i) $\mathrm{Au}$ nanoparticles on a $p-\mathrm{WS}_{2}$ surface and (ii) conducting/ superconducting $\mathrm{YBa}_{2} \mathrm{Cu}_{3} \mathrm{O}_{7-x}$.
\end{abstract}

Atomic force microscopy (AFM) is one of the most powerful tools for surface characterization and has become indispensable for surface and materials science. Sophisticated AFM techniques have been rapidly developed in recent years and the progress is mainly due to the improvements made on the properties of the AFM tips. ${ }^{1}$ For example, electrically conductive layers covering the AFM cantilevers provide the feasibility of synchronous measurement of the topography and the electrical properties of the specimen. ${ }^{2}$ Tips coated with metals are perfect for noncontact Kelvin-mode measurements ${ }^{3}$ and the obtained contact potential difference (CPD) pictures display a high lateral resolution. ${ }^{4}$ However, the mechanical stability of such thin evaporated or sputtered coatings is very low, which results in a short lifetime in the order of a few pictures. ${ }^{5}$ Therefore, hard- and low-resistivity coatings are highly desired and further requirements to the coating for the ideal AFM tip are: good adhesion, pinhole free with uniform thickness, atomic flat, and the coating should not be thicker than $20-30 \mathrm{~nm}$ in order to avoid an increased curvature radius of the tip.

Layers of tetrahedrally bonded amorphous carbon (ta-C), cubic boron nitride $(c-\mathrm{BN})$, and boron carbide $\left(\mathrm{B}_{4} \mathrm{C}\right)$ come into consideration as ideal coatings among the superhard materials. In contrast to chemical vapor deposited diamond, these materials can be grown at low temperature and exhibit an almost atomic flat surface, if they are deposited by physical vapor deposition techniques. ${ }^{6}$ However, ta-C and $c$-BN are insulating materials with specific resistivities in the order of $10^{10} \Omega \mathrm{cm},{ }^{6}$ but $\mathrm{B}_{4} \mathrm{C}$ shows lower values between $10^{3}$ and $10^{9} \Omega \mathrm{cm}$ depending on the microstructure, stoichiometry, and deposition technique used. ${ }^{7,8}$

At this writing, $\mathrm{B}_{4} \mathrm{C}$ films have mainly been grown by various chemical vapor deposition (CVD) techniques ${ }^{8,9}$ and magnetron sputtering ${ }^{10}$ with many different objectives including as a coating for nuclear fusion reactors. The deposited films are amorphous, but these high rate deposition techniques are not suitable for the controlled growth of uniform

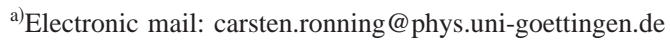

and pinhole-free thin $(<20 \mathrm{~nm})$ films. Further disadvantages of CVD are high growth temperatures and the necessary use of very toxic boron compounds or gases.

In this letter, we report on the properties of $\mathrm{B}_{4} \mathrm{C}$ thin films deposited by mass selected ion beam deposition (MSIBD) at room temperature (RT). ${ }^{11}$

$\mathrm{B}_{4} \mathrm{C}$ thin films were grown on single crystalline silicon substrates by direct deposition of low energy ${ }^{11} \mathrm{~B}^{+}$and ${ }^{12} \mathrm{C}^{+}$ ions at room temperature. Ions were produced in a Sideniustype hot filament source fed with $\mathrm{CO}_{2}$ gas and nontoxic $\mathrm{B}_{2} \mathrm{O}_{3}$ vapor. Ions were accelerated to $30 \mathrm{keV}$, mass separated and electrostatically decelerated down to $20-500 \mathrm{eV}$ before deposition. The deceleration lens system and the substrate holder were mounted in a differentially pumped deposition chamber allowing a pressure below $2 \times 10^{-8} \mathrm{mbar}$ (UHV) during deposition. The films are therefore free of contaminants like oxygen or hydrogen. The details of the UHVdeposition system are described elsewhere. ${ }^{6,12}$ The charge measurement was used to alternately switch the separation magnet between masses ${ }^{11} \mathrm{~B}$ - and ${ }^{12} \mathrm{C}$, so that a constant $\mathrm{B}^{+} \mathrm{C}^{+}$charge ratio was obtained. The substrates were cleaned using acetone and in situ immediately before deposition by sputtering with $1 \mathrm{keV}^{40} \mathrm{Ar}^{+}$ions in order to remove the insulating $\mathrm{SiO}_{2}$ layer. The $\mathrm{B}^{+}: \mathrm{C}^{+}$charge ratio was varied from 0:1 (pure carbon) to 1:0 (pure boron) for the different samples.

The obtained stoichiometry was determined from a series of films deposited on Si single crystal substrates with ion energies of $100 \mathrm{eV}$. The measured B content was derived in situ from Auger electron spectroscopy (AES) without breaking the vacuum and ex situ from Rutherford back scattering (RBS) spectroscopy. Figure 1 (a) shows the $\mathrm{B}^{+} / \mathrm{C}^{+}$ion charge ratio versus the measured boron concentration of the films. It is evident that the stoichiometry of the films follows the 1:1 relation of the ion charge ratio, indicated by the dotted line in Fig. 1(a). Therefore, we are able to grow $\mathrm{B}_{X} \mathrm{C}$ films with any defined and desired stoichiometry. The mass density of $\mathrm{B}_{4} \mathrm{C}$ films was measured by RBS in combination with profilometry and revealed values between 2.0 and 2.5 


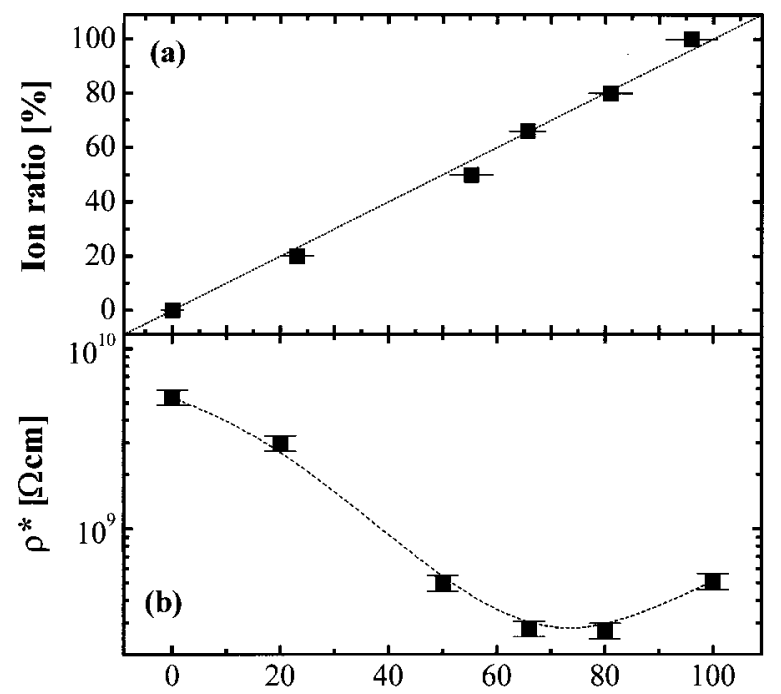

\section{B-concentration [at.\%]}

FIG. 1. (a) $\mathrm{B}^{+} / \mathrm{C}^{+}$ion ratio as a function of the measured $\mathrm{B}$ concentration of the deposited films derived from both in situ AES and ex situ RBS. (b) Value $\rho^{*}$ measured from an ohmic fit to the onset of the forward part of the $I-V$ characteristic of $\mathrm{B}_{X} \mathrm{C}-\mathrm{Si}$ heterojunctions.
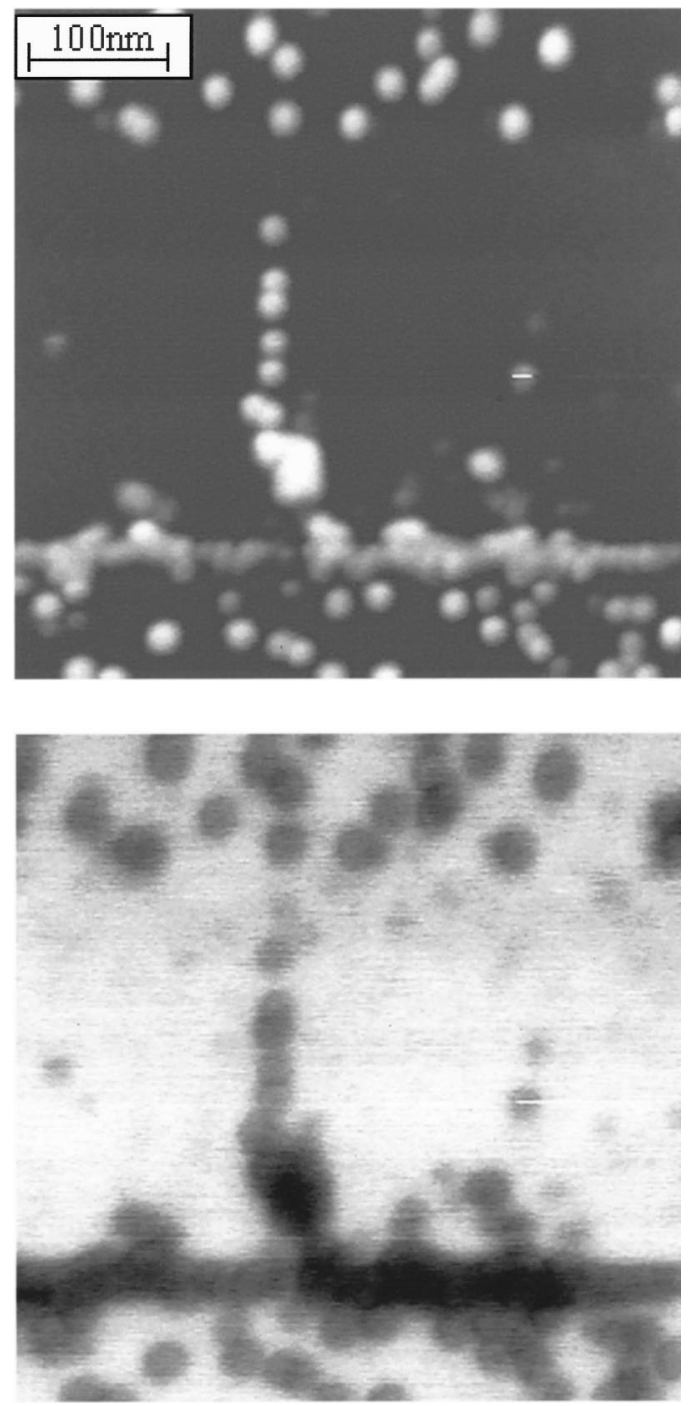

FIG. 2. Topography measured in noncontact mode (top) and corresponding Kelvin signal (bottom) of a manipulated region of a gold covered $p-\mathrm{WS}_{2}$ surface measured with a $\mathrm{B}_{4} \mathrm{C}$-coated $\mathrm{Si}$ cantilever.
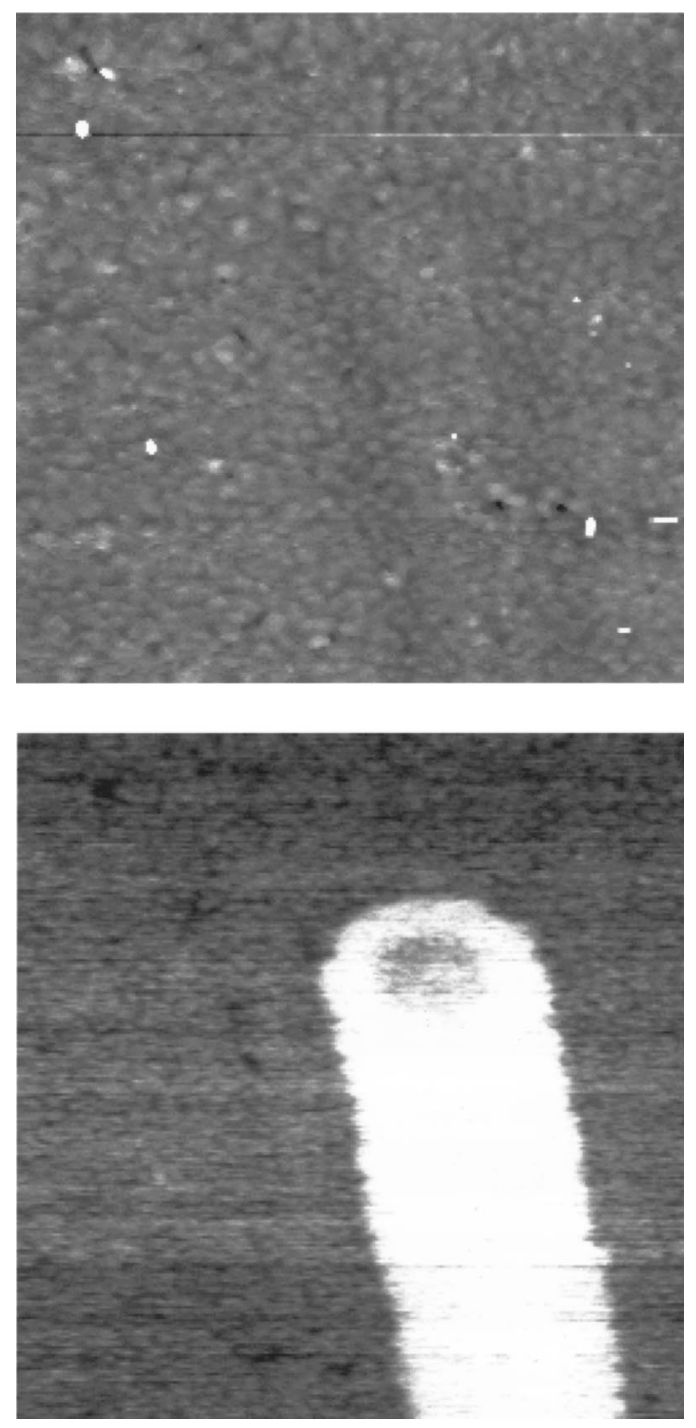

FIG. 3. Topography (top) and CPD (bottom) measured in noncontact mode of a $\mathrm{YBa}_{2} \mathrm{Cu}_{3} \mathrm{O}_{7-x}$ thin film partially modified by laser irradiation. Shown is an area of $10 \mu \mathrm{m} \times 10 \mu \mathrm{m}$.

$\mathrm{g} / \mathrm{cm}^{-3}$, which is in agreement with Ref. 8 and corresponds to the plasmon energy of $25-26 \mathrm{eV}$ determined by electronenergy loss spectroscopy. Infrared spectra of the deposited $\mathrm{B}_{X} \mathrm{C}$ films display a very broad absorption band related to $\mathrm{B}-\mathrm{C}$ bonds around $900-1300 \mathrm{~cm}^{-1}$. The broadness is an indication for the amorphous structure of the grown films. ${ }^{9,10}$

The electrical properties of the $\mathrm{B}_{X} \mathrm{C}$ films were obtained from current-voltage $(I-V)$ curves measured in the dark at RT with evaporated Au contacts as one electrode and the $\mathrm{Si}$ substrate as the other. We used standard $p$-type silicon with a specific resistivity of 5-14 $\Omega \mathrm{cm}$. The diode-like behavior of the obtained $I-V$ curves is in agreement with Ref. 13. However, a quantitative description of the diode characteristic is difficult, because the current transport is mainly limited by three factors: (i) the ohmic resistance of the $\mathrm{Si}$, (ii) the Schottky contact or heterojunction between $\mathrm{Si}$ and $\mathrm{B}_{X} \mathrm{C}$, which is mainly influenced by the size of the mobility gap of the amorphous $\mathrm{B}_{X} \mathrm{C}$, and (iii) the resistance of the $\mathrm{B}_{X} \mathrm{C}$-layer, which may be voltage dependent due to Frenkel-Poole emission or other mechanisms. A detailed analysis of the characteristics will be separately presented ${ }^{14}$ and as a result we show here [Fig. 1(b)] a resistivity-like value $\rho^{*}$ extracted 
TABLE I. Compilation of results evaluated from measurements of the $d C / d z$ distance characteristic of various AFM tips. The effective radius that depends on the working distance describes the radius of the tip curvature relevant for electrostatic measurements. The values in brackets for the new Si tip are estimated and take into account a larger working distance due to the oxide layer. The radius marked with ( $\left.{ }^{a}\right)$ is taken from the manufacturers specifications.

\begin{tabular}{|c|c|c|c|c|c|}
\hline Tip & $\begin{array}{c}\text { Pt-coated } \\
\text { Si } \\
\text { (used) }\end{array}$ & $\begin{array}{c}\mathrm{Si} \\
(\text { new) }\end{array}$ & $\begin{array}{c}\mathrm{Si} \\
\text { (used) }\end{array}$ & $\begin{array}{c}\mathrm{B}_{4} \mathrm{C} \text {-coated } \\
\mathrm{Si} \\
(\text { new })\end{array}$ & $\begin{array}{l}\mathrm{B}_{4} \mathrm{C} \text {-coated } \mathrm{Si} \\
\quad \text { (used after } \\
\text { contact mode) }\end{array}$ \\
\hline Radius (nm) & $74 \pm 5$ & $10^{\mathrm{a}}(25)$ & $79 \pm 5$ & $35 \pm 3$ & $37 \pm 3$ \\
\hline Effective radius (nm) & $30 \pm 1.5$ & $(20 \pm 5)$ & $34 \pm 1.5$ & $17 \pm 1.0$ & $18 \pm 1.0$ \\
\hline Working distance (nm) & $16 \pm 1.6$ & $12(30)$ & $20 \pm 2.0$ & $12 \pm 1.5$ & $13 \pm 1.5$ \\
\hline
\end{tabular}

from an ohmic fit to the onset of the forward part of the $I-V$ characteristic. The resistance of the $\mathrm{B}_{X} \mathrm{C}$ layer contributes to this part of the $I-V$ curve. The value $\rho^{*}$, which was scaled with the contact diameter and the $\mathrm{B}_{X} \mathrm{C}$-layer thickness, is in minimum at a stoichiometry of $\mathrm{B}_{4} \mathrm{C}$ with a value of about $2 \times 10^{8} \Omega \mathrm{cm}$ and, therefore, about two orders of magnitude higher compared to ta- $\mathrm{C}$, showing the much lower resistivity of the $\mathrm{B}_{4} \mathrm{C}$ layer. The trend in Fig. 1(b) is more distinctive for films grown on metal substrates, where the resistivity of ta-C films doped with low concentrations of boron (up to 10 at. \%) already resulted into a 2-4 order of magnitude lower resistivity. ${ }^{15}$ Finally, we deposited $\mathrm{B}_{4} \mathrm{C}$ films on Si substrates as a function of ion energy and we observed an increase of the value $\rho^{*}$ with increasing ion energy.

Evaluating all film properties resulted in the following optimum deposition parameters for coating AFM tips: a stoichiometry of 4:1 $\left(\mathrm{B}_{4} \mathrm{C}\right)$, an ion energy around $100 \mathrm{eV}$ and deposition at RT. Therefore, AFM cantilevers were coated under the these conditions with layers of less than $20 \mathrm{~nm}$ thickness. Such deposition conditions also result into a high compressive stress of several GPa of the layer leading to a dramatic bending of the cantilever. Thus, we coated the cantilevers with a similar layer on the backside. Therefore, the effect was compensated and unbowed cantilevers suitable for AFM were obtained.

Figure 2 (top) shows the topography measured in noncontact mode of a manipulated region of a $p-\mathrm{WS}_{2}$ surface evaporated with gold (a nominal layer thickness of $2 \AA$ for this sample) measured with a $\mathrm{B}_{4} \mathrm{C}$ coated $\mathrm{Si}$ cantilever. Shown in Fig. 2 is an area of $500 \mathrm{~nm} \times 500 \mathrm{~nm}$ and clearly visible are the Au nanoparticles with an average size of less than $30 \mathrm{~nm}$. Prior to the measurement, the gold particles were moved with the same $\mathrm{B}_{4} \mathrm{C}$-coated cantilever operated in contact mode to form the lines of gold clusters. This demonstrates that such cantilevers can be easily used in contact mode without significant wetting of the tip. Furthermore, the tip maintains its properties (i.e., radius) after this procedure showing the high mechanical strength of the coating. Figure 2 (bottom) shows the corresponding Kelvin signal.

Figure 3 shows a noncontact mode AFM measurement of an $\mathrm{YBa}_{2} \mathrm{Cu}_{3} \mathrm{O}_{7-x}$ thin film partially modified by laser irradiation. ${ }^{16}$ Shown in Fig. 3 is an area of $10 \mu \mathrm{m} \times 10 \mu \mathrm{m}$. Topography (top) and CPD (bottom) were measured at the same time using the $\mathrm{B}_{4} \mathrm{C}$-coated $\mathrm{Si}$ tip. The darker areas in the CPD picture correspond to a lower work function. Laser irradiation under an oxygen atmosphere locally increases the oxygen content and the work function, which is visible in the CPD picture. The bright area becomes superconducting be- low $T_{C}$. The topography remains almost uniform, as shown in the top picture of Fig. 3.

Finally, we characterized the $\mathrm{B}_{4} \mathrm{C}$-coated AFM tips and Table I compares the properties of different cantilevers. We would like to note that the radius of new $\mathrm{B}_{4} \mathrm{C}$-coated tips are about a factor 3 larger compared to new $\mathrm{Si}$ tips due to the coating process. Therefore, the lateral resolution is slightly lower, but Si tips are not suitable for Kelvin mode measurements under ambient conditions due to the insulating $\mathrm{SiO}_{2}$ surface layer. On the other hand, the $\mathrm{B}_{4} \mathrm{C}$-coated tips do not show significant wear after use compared to pure $\mathrm{Si}$ and Pt-coated Si tips. The hardness of the tips is only lower compared to cantilevers coated with B-doped CVD diamond, which exhibit comparable electrical properties. ${ }^{17}$ However, the surface morphology of such CVD-diamond coated tips is very rough due to the randomly ordered diamond crystallites of $\mu \mathrm{m}$ size. This results into a low lateral resolution of the tips and considerable variation of the tip properties (especially radius) has been found for different batches and type of probes. ${ }^{17}$

The authors would like to thank J. Eisenmenger for supplying us with the laser-irradiated $\mathrm{YBa}_{2} \mathrm{Cu}_{3} \mathrm{O}_{7-x}$ samples.

${ }^{1}$ See e.g., Atomic Force Microscopy/Scanning Tunneling Microscopy 3, edited by S. H. Cohen (Kluwer-Dordrecht, Academic, 1999).

${ }^{2}$ A. Olbrich, B. Ebersberger, and C. Boit, Appl. Phys. Lett. 73, 3114 (1998).

${ }^{3}$ M. Nonnenmacher, M. P. O’Boyle, and H. K. Wickramasinghe, Appl. Phys. Lett. 58, 2921 (1991).

${ }^{4}$ M. Böhmisch, F. Burneites, A. Rottenberger, J. Zimmermann, J. Boneberg, and P. Leidver, J. Phys. Chem. B 101, 10162 (1997).

${ }^{5}$ M. A. Lantz, S. J. O'Shea, and M. E. Welland, Rev. Sci. Instrum. 69, 1757 (1998).

${ }^{6} \mathrm{H}$. Hofsäss and C. Ronning, in Beam Processing of Advanced Materials, edited by J. Singh, S. M. Copley, and J. Mazumder ASM, (1996), p. 29ff.

${ }^{7}$ A. Lee and P. A. Dowden, Appl. Phys. A: Solids Surf. 58, 223 (1994).

${ }^{8}$ A. O. Sezer and J. I. Brand, Mater. Sci. Eng., B 79, 191 (2001).

${ }^{9}$ S. V. Despande, E. Gulari, S. J. Harris, and A. M. Weiner, Appl. Phys. Lett. 65, 1757 (1994).

${ }^{10}$ D. C. Reigada, R. Prioli, L. Jacobsohn, and F. L. Freire, Diamond Relat. Mater. 9, 489 (2000).

${ }^{11}$ H. Hofsäss, J. Boneberg, and P. Leiderer, German Patent No. 19, 752, 202.5 (25 November 1997).

${ }^{12}$ H. Hofsäss, H. Binder, T. Klumpp, and E. Recknagel, Diamond Relat. Mater. 3, 137 (1994).

${ }^{13}$ S. Lee, J. Mazurowski, G. Ramseyes, and P. A. Dowben, J. Appl. Phys. 72, 4925 (1992).

${ }^{14}$ C. Ronning and H. Hofsäss, Proceedings of the 12th SMMIB, 9-14 Sept. 2001, Marburg, Germany (unpublished).

${ }^{15}$ C. Ronning, U. Griesmeier, M. Gross, H. Hofsäss, R. G. Downiny, and G. P. Lamaze, Diamond Relat. Mater. 4, 666 (1995).

${ }^{16} \mathrm{~J}$. Eisenmenger, J. Eisenmenges, J. Zimmermann, J. Schiessling, U. Bolz, and P. Leideres, Adv. Solid State Phys. 39, 403 (1999).

${ }^{17}$ T. Trenkler et al., J. Vac. Sci. Technol. B 18, 418 (2000). 